\title{
Force-field-based minimizations of protein-ligand complexes in the blink of an eye
}

\author{
Lennart Heinzerling, Matthias Rarey ${ }^{*}$ \\ From 8th German Conference on Chemoinformatics: 26 CIC-Workshop \\ Goslar, Germany. 11-13 November 2012
}

Basing protein-ligand optimizations on molecular mechanics force fields yields high accuracy at the cost of speed. We address this dilemma by circumventing unnecessary calculations and by harvesting the computational power of graphics processor units (GPUs). This novel computational architecture is well suited for parallelizing and massively speeding up force-field-based minimization procedures. Our endeavor encompasses fundamental adaptions of formerly CPU-based methods in order to take the GPU-specific programming paradigms into account. This results in force-field kernels uniquely targeted at the efficient optimization of protein-ligand complexes in the context of a mostly GPU-based procedure. This procedure constitutes an improvement of our recently published method[1] which focuses on complex optimizations with rigid proteins. The new version presented here features side chain flexibility in the protein's active site. Additionally, it allows to guide the optimization procedure by considering pharmacophoric-type geometric constraints. In this way, we exploit knowledge about binding modes and conformational preferences. In detail, preferred dihedral angles are annotated to rotatable bonds and selected key hydrogen bond interactions are marked and conserved.

We demonstrate the procedure's potential by performing a large-scale docking run on the Astex-non-native set [2]. By optimizing the resulting protein-ligand complexes, we significantly shift the more promising conformations towards the crystal structure geometry of the complex. In spite of using the full point-to-point potential, an optimization run for a protein-ligand complex finishes in less than $500 \mathrm{~ms}$ on average.

Published: 22 March 2013

\footnotetext{
* Correspondence: rarey@zbh.uni-hamburg.de

Center for Bioinformatics, University of Hamburg, Hamburg, Germany
}

References

1. Heinzerling $L$, Klein $R$, Rarey M: Fast Force Field-based Optimization of Protein-Ligand Complexes with Graphics Processor. J Comp Chem 2012, 33(32).

2. Verdonk ML, Mortenson PN, Hall RJ, Hartshorn MJ, Murray CW: ProteinLigand Docking against Non-Native Protein Conformers. J Chem Inf Model 2008, 48:2214-2225.

doi:10.1186/1758-2946-5-S1-P14

Cite this article as: Heinzerling and Rarey: Force-field-based minimizations of protein-ligand complexes in the blink of an eye. Journal of Cheminformatics 2013 5(Suppl 1):P14.

\section{Publish with ChemistryCentral and every scientist can read your work free of charge \\ "Open access provides opportunities to our colleagues in other parts of the globe, by allowing anyone to view the content free of charge." \\ W. Jeffery Hurst, The Hershey Company. \\ - available free of charge to the entire scientific community \\ - peer reviewed and published immediately upon acceptance \\ - cited in PubMed and archived on PubMed Central \\ - yours - you keep the copyright \\ Submit your manuscript here: \\ http://www.chemistrycentral.com/manuscript/

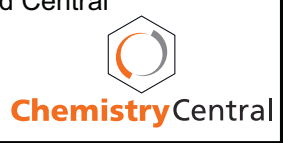

